\title{
Implementation of an Add-on Device that Monitors the Sound of a Machine Tool and Automatically Suppresses Chatter
}

\author{
Wei-Chen Lee, ${ }^{*}$ Hsu-Cheng Cheng, and Ching-Chih Wei \\ Department of Mechanical Engineering, National Taiwan University of Science and Technology, \\ Taipei 10607, Taiwan
}

(Received April 20, 2019; accepted September 4, 2019)

Keywords: chatter suppression, machine monitoring, CNC controller, add-on device

The application of the Industrial Internet of Things in a factory to connect machines is a topic that has attracted considerable attention in recent years. After connecting the machines, we can usually obtain the data from the controllers of the machines. However, the controller manufacturers usually do not allow users to remotely change the status of the controllers owing to safety or other reasons, which makes it challenging to enable the machines to adapt to the environment by using sensors. With the acknowledgment of this problem, the objective of this study was to develop an add-on device to provide an alternative solution to control some of the machine behaviors. Our device, based on an embedded system, is equipped with sensors and actuators, including a microphone, a CMOS webcam, stepper motors, and a pneumatic cylinder. After the device is installed on the control panel of a computer numerical control (CNC) machine tool, it can allow users to execute the machining process to cut the materials remotely and monitor the process automatically. Additionally, the device can detect chatter by using the microphone, which is the audio sensor, and suppress chatter automatically by adjusting the spindle speed and feed rate knobs through the mechanism on the device. From the experimental results, the surface roughness of a workpiece can be improved by about $68 \%$ after the chatter suppression. The information displayed on the control panel can also be captured by a webcam and processed with optical character recognition (OCR) so that it can be saved as a text file in our device. This information can then be used for the further improvement of the manufacturing process of material cutting.

\section{Introduction}

A computer numerical control (CNC) milling machine tool is commonly used for metal cutting in a machine shop. During the cutting process, if cutting parameters are not set properly, chatter between the workpiece and the cutter will occur, and the machining sound will be abnormally loud or sharp. This undesirable phenomenon will not only cause a rough surface on the workpiece but also degrade the cutting tool. These disadvantages lead to an increase in the cost of production.

*Corresponding author: e-mail: wclee@mail.ntust.edu.tw

https://doi.org/10.18494/SAM.2019.2501 
Chatter is one type of vibration resulting from the relative movement between the workpiece and the cutting tool during the cutting process. From an energy perspective, this vibration can be described as a phenomenon of energy aggregation. Chatter is affected by many factors, including the material properties of the cutting tool and workpiece, the stiffness of the machine tool, the stiffness of clamping, the stiffness of the spindle, the depth of cut, cutting width, and spindle speed. Taylor stated that chatter is the "most obscure and delicate of all problems facing the machinist."(1) Rough surfaces and tool wear caused by chatter are undesirable results for machine shops. Many researchers have been studying chatter recognition and suppression techniques, and developed various methods to actively or passively modify the system behavior to solve the chatter problem. ${ }^{(2-9)}$ Faassen et al. ${ }^{(10)}$ showed that the milling model of a machine is dependent on the spindle speed; they used the D-partitioning method to find the critical depth of cut for specific spindle speeds. Grossi et al. ${ }^{(11)}$ proposed the spindle speed rampup test to obtain a stability lobe diagram without requiring knowledge of the process. In this method, the spindle speed was continuously increased with a constant depth of cut until chatter occurred. Delio et al. ${ }^{(12)}$ compared four different sensors, namely, microphones, dynamometers, displacement probes, and accelerometers, and found that a microphone was an excellent sensor for detecting chatter. Munoa et al. ${ }^{(13)}$ discussed spindle speed variations of chatter suppression techniques in an end-milling process. Regarding the detection of chatter, different sensors have been used, including accelerometers, dynamometers, and microphones. ${ }^{(11)}$ For example, Faassen et al. ${ }^{(10)}$ used a microphone in their experiment to detect chatter. From the above discussion, suppressing chatter is a critical requirement in the machining process.

Some high-end CNC machine tools are equipped with sensors, such as microphones or accelerometers, and the sensors can directly send feedback to CNC controllers to automatically suppress chatter. Similarly, Han et al. ${ }^{(14)}$ proposed a SMART CNC control system that can also take vibrational signals into account to suppress chatter. Under the constraint that most of the low-end or dated CNC controllers lack the feature of automatic process adjustment, the immediate solution to chatter suppression is to have a technician monitor the milling process and manually adjust the spindle speed or other cutting parameters for abnormally sharp machining sounds. This solution may not be acceptable owing to the cost. Kim et $a l .{ }^{(15)}$ developed an embedded chatter-sensing device with a digital signal processor (DSP) to automatically detect chatter by using accelerometers. The DSP sends commands directly to the $\mathrm{CNC}$ controller to suppress chatter. However, the difficulty in implementing this method is that the many $\mathrm{CNC}$ controllers do not allow the commands from the external device to control the conditions of the CNC machine. These difficulties are common, especially for legacy or lowend CNC machines.

Regarding such difficulties, the objective of this research was to develop an add-on device that can be installed on the control panel of a CNC milling machine. The device can automatically monitor the manufacturing process and adjust manufacturing parameters when chatter is detected. The advantage of the device is that there is no need to access the CNC controller, so that the device can be applied to most of the $\mathrm{CNC}$ controllers. 


\section{Materials and Methods}

As shown in Fig. 1, our device is equipped with the following functions: button pushing, machining sound monitoring, spindle speed and feed rate adjustment, screen monitoring, and tool location acquisition. The device, based on an embedded system, can allow users to execute the machining process and monitor it remotely. The device can also detect and suppress chatter. When an abnormally sharp sound occurs, the device can automatically adjust the spindle speed or feed rate to alter machining parameters to alleviate the undesirable machining condition. Moreover, the information displayed on the screen of the control panel can be acquired by the webcam of the device so that the codes that cause the chatter can be saved in a database for further analysis.

The embedded system used for the device proposed in the study was myRIO (National Instruments, USA). This embedded system can perform motion control as well as data acquisition. The hardware of the device can be categorized into three main units: the remote panel control unit, the machining sound monitoring and knob adjustment unit, and the screen monitoring and information acquisition unit. The completed add-on device, which was installed on the controller of the CNC machining center, is shown in Fig. 2. Detailed descriptions of each unit of the device are found in the following section.

To achieve the button-pushing behavior for the remote panel control unit, we adopted an $X-Y$ table mechanism to move a pen-type pneumatic cylinder, which served as the actuator for button pushing. The advantages of applying the pneumatic cylinder as the actuator are its short response time and light weight. In addition, the pressurized air required for the cylinder can be easily obtained from the CNC machine. The $X-Y$ motion is powered by two stepper motors.

We used a microphone as the audio sensor for monitoring the sound of the machining process-induced vibration. The microphone is connected to the audio input of the embedded system so that the sound signal can be directly processed by the embedded system. The microphone was installed inside the machining center for better detection. The sound acquired

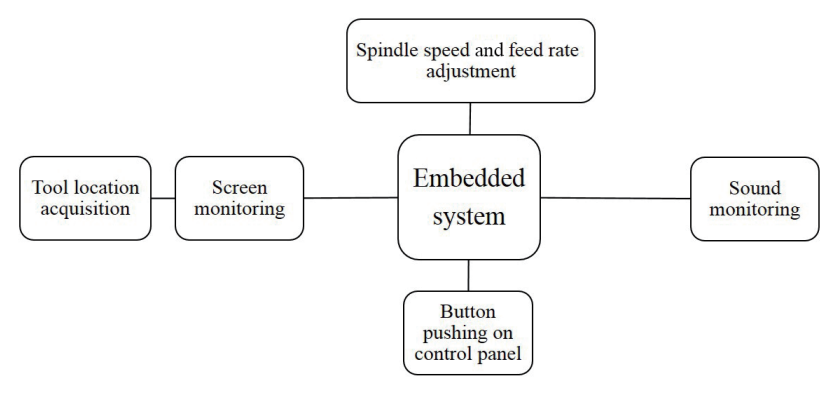

Fig. 1. Structure of the add-on device.

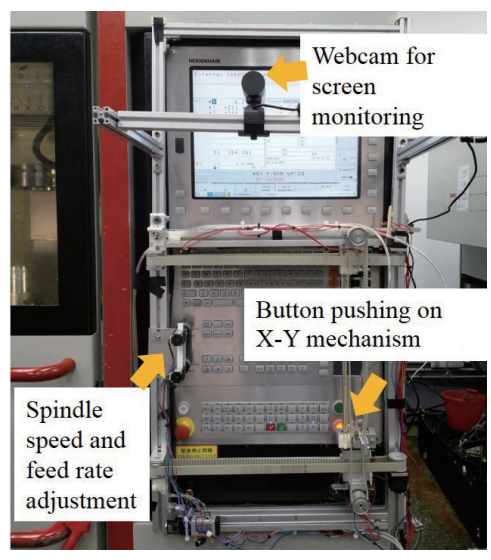

Fig. 2. (Color online) Screen monitoring, spindle speed and feed rate adjustment, and button-pushing functions on the add-on device. 
by the microphone may include the sound of chatter, the sound from the environment, and the sound from various sources of the machining center. In this research, we used fast Fourier transform (FFT) to decompose sound signals to obtain chatter signals. After the sound of chatter is detected, a knob adjustment mechanism enables the change of cutting parameters via the knobs on the control panel. We used two such mechanisms to turn the spindle speed and feed rate knobs on the CNC control panel. The turning motion is achieved by using stepper motors. The plastic sockets are attached to the shaft of the motor and connected to the knobs on the control panel, as shown in Fig. 3.

For the screen monitoring and information acquisition unit, we adopted a $1080 \mathrm{p}$ webcam (Microsoft LifeCam Studio) with a CMOS sensor to capture the information displayed on the screen of the CNC control panel when chatter occurred. The webcam was connected to the embedded system through a USB and installed in front of the screen of the CNC controller, as shown in Fig. 2.

We developed a program to achieve the functions of the device. The program was developed in LabVIEW, which is the developing environment mainly for the embedded system that we used. The functions of the device are listed as follows:

- The user can remotely push the buttons on the control panel of the CNC controller through the $X-Y$ table mechanism and pneumatic cylinder. The location of each button was calibrated so that the user can click the virtual buttons on the graphical user interface of the program, and the pneumatic cylinder will subsequently be moved to the correct position to press the buttons on the control panel.

- The machining sound is acquired as voltage signals by the microphone; the FFT function in LabVIEW was applied to process the signals to transform them from the time domain to the frequency domain. A high-amplitude spike occurs if chatter is detected during the machining process. On the basis of this spike phenomenon, a threshold of amplitude can be set in the frequency domain to determine the initiation of chatter suppression. In other

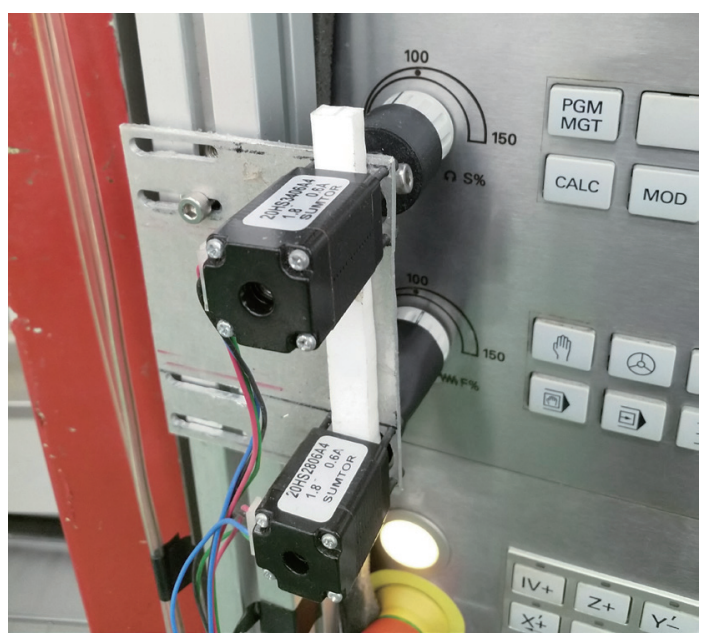

Fig. 3. (Color online) The knob adjustment mechanism is composed of stepper motors and plastic sockets. The upper knob is the spindle speed knob and the lower one is the feed rate knob. 
words, if an amplitude over this threshold is detected within the frequency region of interest and the signal continues for a predefined period of time, the device will recognize the occurrence of chatter and send commands to the knob adjustment mechanism to change the spindle speed and feed rate to alleviate this severe and undesirable cutting condition. After the amplitude of the spike decreases to a level lower than the threshold, the device will assume the decrease as an indication of the successful suppression of chatter and stop altering these two cutting parameters.

- The screen of the control panel is captured using the webcam, and the image is processed when there is a warning message displayed on the screen, or the chatter is detected or suppressed. Optical character recognition (OCR) is used to convert the tool locations displayed on the screen into texts, and the information will be saved as text files. The information is useful for $\mathrm{CNC}$ users to analyze and improve the machining process.

\section{Results and Discussion}

To validate the feasibility of the add-on device developed in this research, we installed the device on the control panel of the CNC machining center (Quaser UX-300), as shown in Fig. 4, to experiment with automatic chatter detection and suppression. In the experiment, straight-line milling was performed under the condition that chatter would occur, in order to test the chatter detection and suppression function of the device. After that, the roughness of the milled surface was measured to determine the improvement of the surface roughness by using this device.

For the milling process, a two-flute cobalt end mill of $6 \mathrm{~mm}$ diameter and $50 \mathrm{~mm}$ length was used to cut a workpiece made of low-carbon steel in a straight line. The cutting parameters listed in Table 1 were deliberately set to induce chatter. The depth of cut was set at $2 \mathrm{~mm}$ and the cutting width was $5 \mathrm{~mm}$. The spindle speed and feed rate were $8200 \mathrm{rpm}$ and $1350 \mathrm{~mm} / \mathrm{min}$, respectively. After we executed the milling process, the amplitude of the sound signals in the

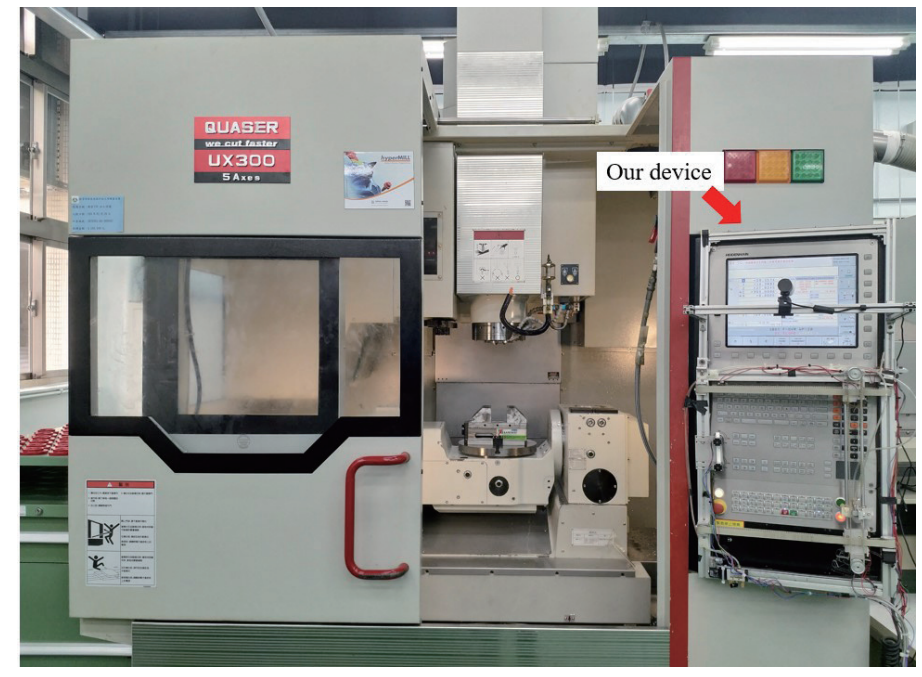

Fig. 4. (Color online) The add-on device was installed on the control panel of the CNC machining center. 
frequency domain increased to a value higher than the threshold. Subsequently, the embedded system on the device initiated the knob adjustment. The knob adjustment mechanism started to alter the spindle speed and feed rate. Here, we adopted the strategy to reduce both the spindle speed and feed rate to suppress the chatter. The spindle speed was decreased from 8200 to $7277 \mathrm{rpm}$, and the feed rate was decreased from 1350 to $1298 \mathrm{~mm} / \mathrm{min}$. These changes are listed in Table 2. The amplitude of the FFT-processed signals then dropped below the threshold and the adjustment stopped.

The milled surface of this straight cut is shown in Fig. 5. The surface on the right was milled when the chatter occurred and that on the left was milled when the chatter was suppressed. As shown in the figure, more tool marks can be found on the surface when the chatter occurred because of the relative movement between the tool and the workpiece.

The roughness of the workpiece surface was then measured with a surface roughness tester (HOMMEL-ETAMIC T8000). The parameters used for surface roughness measurement are listed in Table 3. The measurement length was $4.8 \mathrm{~mm}$ and the probe diameter was $0.5 \mu \mathrm{m}$. The cutoff length was $0.8 \mathrm{~mm}$ and the sampling interval was $0.5 \mu \mathrm{m}$. The surface roughness when the chatter occurred was $1.86 \mathrm{Ra}(\mu \mathrm{m})$, as shown in Fig. 6(a), and when the chatter was suppressed, it was $0.60 \mathrm{Ra}(\mu \mathrm{m})$, as shown in Fig. 6(b). The roughness of the workpiece milled surface was improved by about $68 \%$.

The device also successfully captured the image of the screen of the control panel at the instant of chatter being detected, as shown in Fig. 7(a). After OCR, the program that we developed using LabVIEW can save the recognized tool locations in a text file, as shown

Table 1

Cutting parameters for the milling process.

\begin{tabular}{cccc}
\hline Depth of cut & Spindle speed & Feed rate & Cutting width \\
\hline $2 \mathrm{~mm}$ & $8200 \mathrm{rpm}$ & $1350 \mathrm{~mm} / \mathrm{min}$ & $5 \mathrm{~mm}$ \\
\hline
\end{tabular}

Table 2

Comparison of cutting parameters before and after the suppression of chatter.

\begin{tabular}{lcc}
\hline & Before suppression & After suppression \\
\hline Spindle speed $(\mathrm{rpm})$ & 8200 & 7277 \\
Feed rate $(\mathrm{mm} / \mathrm{min})$ & 1350 & 1298 \\
\hline
\end{tabular}

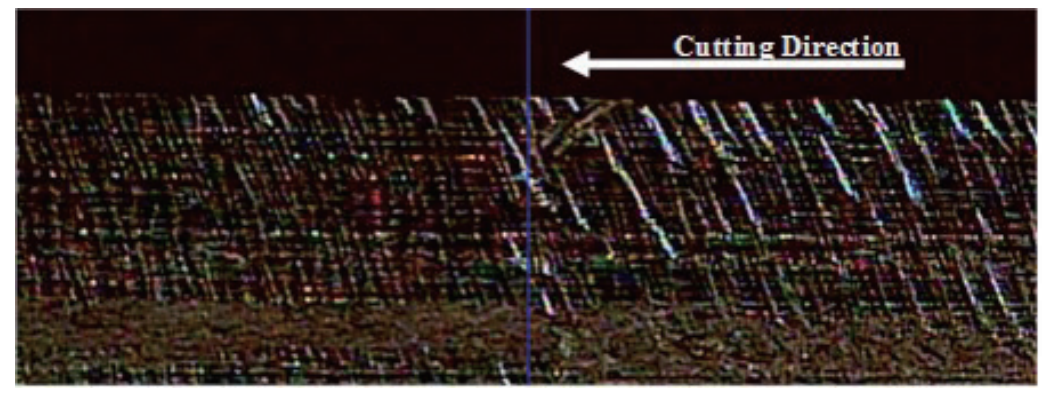

Fig. 5. (Color online) Comparison of the milled surface with (on the right) and without (on the left) chatter. 
Table 3

Parameters used for surface roughness measurement.

\begin{tabular}{cccc}
\hline Measurement length & Probe diameter & Cutoff length $\lambda c$ & Sampling interval \\
\hline $4.8 \mathrm{~mm}$ & $0.5 \mu \mathrm{m}$ & $0.8 \mathrm{~mm}$ & $0.5 \mu \mathrm{m}$ \\
\hline
\end{tabular}

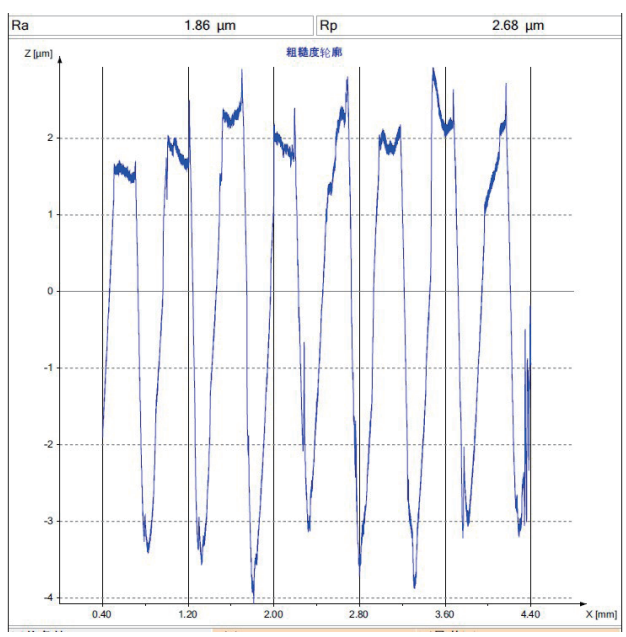

(a)

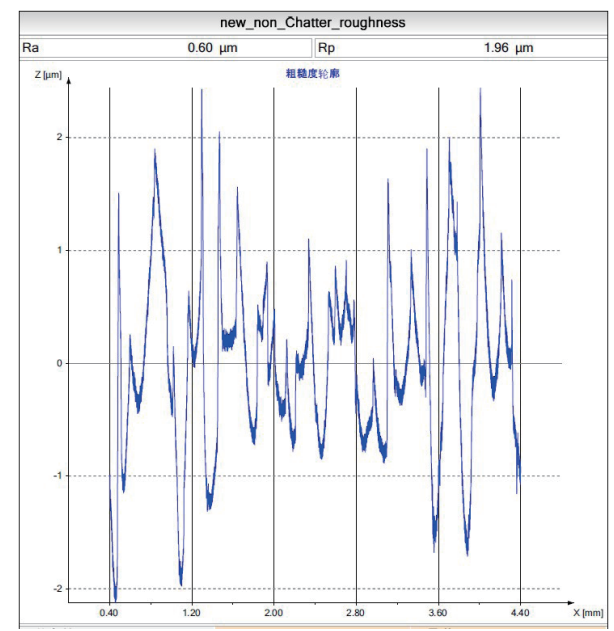

(b)

Fig. 6. (Color online) Roughness of the milled surface (a) with chatter and (b) without chatter.

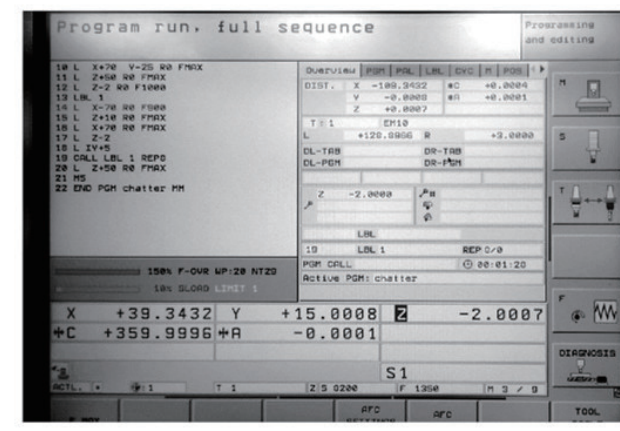

(a)

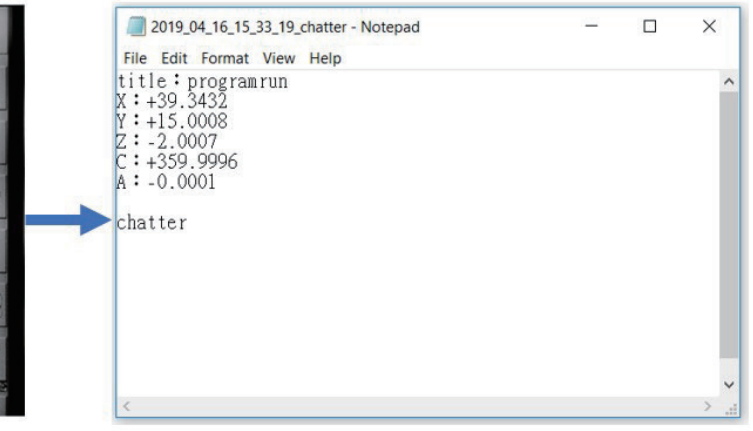

(b)

Fig. 7. (Color online) (a) Captured screen image at the instant of chatter being detected; (b) text file containing the tool position from the image by using OCR.

in Fig. 7(b). This information can provide users with useful information to improve CAM programming and analyze cutting parameters for stable cutting.

The innovation of the device is that it can be installed on any CNC controller with some minor adjustment to control $\mathrm{CNC}$ machines manually or automatically without the need to obtain approval from the manufacturers of $\mathrm{CNC}$ controllers. Doing so can upgrade a regular CNC machine to that with an automatic chatter suppression feature, which usually can only be found in high-end CNC machines. Also, technicians can remotely control and monitor CNC machines with the help of the add-on device so that the workload for them can be substantially reduced. 


\section{Conclusions}

In this study, an add-on device that can detect and suppress chatter was developed. The device can be installed on the control panel of a CNC machine. With the use of a microphone as the audio sensor, the device can detect chatter while the materials are cut, by monitoring the machining sound, and suppress chatter automatically by adjusting the spindle speed and feed rate knobs. Experimental results demonstrated that the device can perform chatter detection and suppression as expected. The surface roughness can also be improved from 1.86 to $0.60 \mathrm{Ra}$ ( $\mu \mathrm{m})$.

The device proposed in this paper can be used to directly access legacy or unconnected $\mathrm{CNC}$ controllers. Therefore, the device may be a solution for realizing the Industrial Internet of Things (IIoT) in a factory with various connected and unconnected machines.

\section{Acknowledgments}

The authors wish to thank the Ministry of Science and Technology, Republic of China, for financial support of this research under Grant No. MOST 107-2218-E-011-002.

\section{References}

1 F. W. Taylor: On the Art of Cutting Metals (ASME, New York, 1907) p. 148.

2 G. Quintana and J. Ciurana: Int. J. Mach. Tools Manuf. 51 (2011) 363. https://doi.org/10.1016/ j.ijmachtools.2011.01.001

3 M. Siddhpura and R. Paurobally: Int. J. Mach. Tools Manuf. 61 (2012) 27. https://doi.org/10.1016/ j.ijmachtools.2012.05.007

4 L. Ding, Y. Sun, and Z. Xiong: J. Manuf. Sci. Eng. 140 (2018) 121003. https://doi.org/10.1115/1.4041248

5 A. Iglesias, Z. Dombovari, G. Gonzalez, J. Munoa, and G. Stepan: Materials 12 (2018) 112. https://doi. org $/ 10.3390 /$ ma12010112

6 P. Albertelli, L. Braghieri, M. Torta, and M. Monno: Mech. Syst. Sig. Process. 123 (2019) 26. https://doi. org/10.1016/j.ymssp.2019.01.002

7 X. Beudaert, K. Erkorkmaz, and J. Munoa: CIRP Ann. 68 (2019) 423. https://doi.org/10.1016/j.cirp.2019.04.010

8 S. Wan, X. Li, W. Su, J. Yuan, J. Hong, and X. Jin: Precis. Eng. 57 (2019) 203. https://doi.org/10.1016/ j.precisioneng.2019.04.007

9 X. Zhang, Z. Yin, J. Gao, J. Liu, R. X. Gao, H. Cao, and X. Chen: J. Manuf. Sci. Eng. 141 (2019) 051003. https://doi.org/10.1115/1.4043020

10 R. P. H. Faassen, N. van de Wouw, J. A. J. Oosterling, and H. Nijmeijer: Int. J. Mach. Tools Manuf. 43 (2003) 1437. https://doi.org/10.1016/s0890-6955(03)00171-8

11 N. Grossi, A. Scippa, L. Sallese, R. Sato, and G. Campatelli: Int. J. Mach. Tools Manuf. 89 (2015) 221. https:// doi.org/10.1016/j.ijmachtools.2014.11.013

12 T. Delio, J. Tlusty, and S. Smith: J. Manuf. Sci. Eng. 114 (1992) 146. https://doi.org/10.1115/1.2899767

13 J. Munoa, X. Beudaert, Z. Dombovari, Y. Altintas, E. Budak, C. Brecher, and G. Stepan: CIRP Ann. 65 (2016) 785. https://doi.org/10.1016/j.cirp.2016.06.004

14 Z. Han, H. Jin, D. Han, and H. Fu: Int. J. Adv. Manuf. Technol. 89 (2017) 2731. https://doi.org/10.1007/s00170016-9863-y

15 D. H. Kim, J. Y. Song, S. K. Cha, and H. Son: J. Mech. Sci. Technol. 25 (2011) 2623. https://doi.org/10.1007/ s12206-011-0737-9 